\title{
Comparison of ropivacaine and fentanyl toxicity in human fibroblasts
}

\author{
Andreas Ficklscherer, Birte Sievers, Julia Redeker, Mehmet F. Gülecyüz, Alexander Paulus, \\ Matthias F. Pietschmann, Peter E. Müller
}

Department of Orthopedics, Ludwig-Maximilians-University of Munich, Germany

Submitted: 5 January 2012

Accepted: 17 October 2012

Arch Med Sci 2013; 9, 3: 576-580

DOI: 10.5114/aoms.2013.35339

Copyright $\odot 2013$ Termedia \& Banach

\section{Abstract}

Introduction: Although ropivacaine and fentanyl are commonly administered intra-articularly after knee or shoulder arthroscopy for postoperative pain control, there are no studies investigating the toxicity of ropivacaine and fentanyl on human fibroblasts (hF).

Material and methods: Human fibroblasts were seeded in monolayer triple flasks at a density of $10^{4}$ cells $/ \mathrm{cm}^{2}$ and plated into 96 plates at a density of 5000 cells per well. After fully aspirating the culture medium $200 \mu \mathrm{l}$ of ropivacaine or fentanyl in its corresponding concentration or culture medium only was added to each well. After 30 min ropivacaine or fentanyl was removed and fresh culture medium was added. Fibroblast mitochondrial activity and apoptosis marker level were evaluated after $1 \mathrm{~h}, 24 \mathrm{~h}$ and 7 days.

Results: We found a significant decrease in mitochondrial activity after 7 days when exposed to $0.5 \%$ ropivacaine. Mitochondrial activity after $1 \mathrm{~h}, 24 \mathrm{~h}$ and 7 days was significantly decreased when fibroblasts were exposed to $0.05 \%$ fentanyl. Also, a significant decrease in mitochondrial activity was observed $1 \mathrm{~h}$ after exposure to $0.025 \%$ fentanyl. Cell viability remained unchanged at any other point in time. A significant increase of caspase-3, as a marker of apoptosis, was only present after exposure to $0.5 \%$ ropivacaine after 7 days.

Conclusions: These data suggest that both drugs have a concentration-dependent effect on mitochondrial activity in $\mathrm{hF}$ in vitro. This effect is more pronounced with fentanyl. Because the cytotoxicity of fentanyl, without the anticipated increase of caspase-3 as an apoptosis marker, remains unclear, we cannot support fentanyl as an alternative to ropivacaine.

Key words: postoperative intraarticular anaesthesia, postoperative pain control.

\section{Introduction}

Postoperative pain management following knee or shoulder arthroscopy can be a challenge. Intra-articular injection of local anaesthetics is regularly used to enhance postoperative analgesia following arthroscopy and has been shown to offer effective and safe postoperative pain relief [1-3]. At the present time, bupivacaine is probably the best studied and most commonly used local anaesthetic for this purpose [4]. However, several recent studies have demonstrated that even a brief exposure to bupivacaine may result in chondrotoxicity [3, 5-8] leading to chondrolysis [7, 8], a devastating condition of rapid chondrocyte death over a short period of time which ultimately leads to cartilage damage and progressive joint degeneration.

\author{
Corresponding author: \\ Dr. Andreas Ficklscherer \\ Department of Orthopedics \\ Ludwig-Maximilians-University \\ of Munich \\ Marchioninistr. 15 \\ 81377 Munich, Germany \\ Phone: +49 8970950 \\ E-mail: andreas.ficklscherer@ \\ med.uni-muenchen.de
}


Promising alternatives to amide-type local anaesthetics are opioids such as morphine or fentanyl. As demonstrated in several studies, endogenous as well as exogenous opioid agonists have peripheral antinociceptive effects in inflamed tissue by interacting with $\kappa, \delta$ and $m \mu$ receptors and have furthermore been used for intra-articular analgesia with favourable outcomes [9-14].

Previous studies focused on the impact of local anaesthetics on chondrocytes. Since fibroblasts play a crucial role in tissue healing and might be aggrieved by the injected analgesic agent, we were interested in the effects on human fibroblasts. Only a few studies exist evaluating the effects of local anaesthetics $[1,15]$ on fibroblasts using analgesic concentrations as applied in clinical settings. Until now there are no studies focusing on the effects of opioids on human fibroblasts. We chose to investigate the viability of human fibroblasts after exposure to ropivacaine, being the less toxic local anaesthetic of the amide group [3], and fentanyl.

The purpose of this study was to investigate possible cytotoxic effects of ropivacaine and fentanyl on human fibroblasts in vitro.

\section{Material and methods}

\section{Drug exposure and proliferation of fibroblasts}

Human fibroblasts (Provitro, Berlin, Germany) were seeded in monolayer triple flasks at a density of $10^{4}$ cells $/ \mathrm{cm}^{2}$ in Dulbecco's modified Eagle's medium (DMEM; Invitrogen, Carlsbad, CA, USA) containing $10 \%$ fetal calf serum (PAA, Pasching, Austria) and $50 \mathrm{U} / \mathrm{ml}$ penicillin/streptomycin (SigmaAldrich, Germany). Twenty-four hours before experimental treatment, cells were visually checked under phase microscopy to ensure a proper cell morphology consistent with differentiated fibroblasts. Cells were then replated into 96-well plates at a density of 5000 cells per well.

Cell cultures were divided into subgroups, each subgroup consisting of 6 wells with 5000 cells per well: $0.5 \%, 0.25 \%, 0.125 \%$ ropivacaine, $0.05 \%$, $0.025 \%$ and $0.0125 \%$ fentanyl. A DMEM-only $(10 \%$ fetal calf serum (PAA, Pasching, Austria) and $50 \mathrm{U} /$ $\mathrm{ml}$ penicillin/streptomycin (Sigma-Aldrich, Germany)) group served as a control (Table I). This protocol was similar to the one described by Piper et al. [3]. In short, culture medium (DMEM) was fully aspirated; $200 \mu \mathrm{l}$ of ropivacaine or fentanyl in its corresponding concentration or DMEM only (control group) was added to each well. Cells were incubated in $5 \% \mathrm{CO}_{2}$ at $37^{\circ} \mathrm{C}$ for $30 \mathrm{~min}$. After $30 \mathrm{~min}$ the treatment solution (ropivacaine or fentanyl) was removed and fresh culture medium was added. The same protocol was applied to all samples.

Samples were returned to the incubator and mitochondrial activity was evaluated after $1 \mathrm{~h}$, $24 \mathrm{~h}$ and 7 days using a WST-1 assay [16] (Cell Proliferation Reagent WST-1, Roche, Germany). Medium was replaced with DMEM with $10 \%$ WST-1 agent. Samples were returned to the incubator for another $2.5 \mathrm{~h}$. The WST-1 assay is a colorimetric test based on cleavage of the tetrazolium salt WST-1 by mitochondrial dehydrogenases in viable cells into orange formazan. The level of orange formazan produced increases when mitochondrial activity increases and can be quantified using an ElisaReader (MWG-Biotech, Ebersberg, Germany) at $450 \mathrm{~nm}$, with a reference wavelength at $690 \mathrm{~nm}$.

\section{Gene expression of apoptosis-specific proteins}

In a LightCycler (Roche Applied Science, Mannheim, Germany) the following primers were used: glyceraldehyde-3-phosphate-dehydrogenase (GAPDH): sense: $5^{`}$-TGC ACC ACC AAC TGC TTA GC-3`; antisense: 5 '-GGC ATG GAC TGT GGT CAT GAG-3` [17]. The primers for the apoptosis-specific proteins, caspase- 3 and PARP-1, were purchased from Search-LC (Heidelberg, Germany); the sequences were not provided by the company. Total RNA was directly isolated from fresh fibroblasts using the RNeasy Mini Kit (Qiagen, Hilden, Germany). For cDNA synthesis, $1 \mu \mathrm{g}$ of total RNA was reverse-transcribed using the Transcriptor High Fidelity cDNA Synthesis Kit (Roche Applied Science). Amplification reactions were performed using a LightCycler

Table I. Study set-up. At each point of time and for each dilution we had $6 \times 5000$ cells

\begin{tabular}{|lclll|}
\hline Drug & Dilution [\%] & \multicolumn{3}{c|}{ Point of time } \\
\cline { 2 - 5 } & & $1 \mathrm{~h}$ & $24 \mathrm{~h}$ & 7 days \\
\hline Ropivacaine & 0.5 & $6 \times 5000$ cells & $6 \times 5000$ cells & $6 \times 5000$ cells \\
\cline { 2 - 5 } & 0.25 & $6 \times 5000$ cells & $6 \times 5000$ cells & $6 \times 5000$ cells \\
\cline { 2 - 5 } & 0.125 & $6 \times 5000$ cells & $6 \times 5000$ cells & $6 \times 5000$ cells \\
\hline Fentanyl & 0.05 & $6 \times 5000$ cells & $6 \times 5000$ cells & $6 \times 5000$ cells \\
\cline { 2 - 5 } & 0.025 & $6 \times 5000$ cells & $6 \times 5000$ cells & $6 \times 5000$ cells \\
\hline DMEM & 0.0125 & $6 \times 5000$ cells & $6 \times 5000$ cells & $6 \times 5000$ cells \\
\hline
\end{tabular}




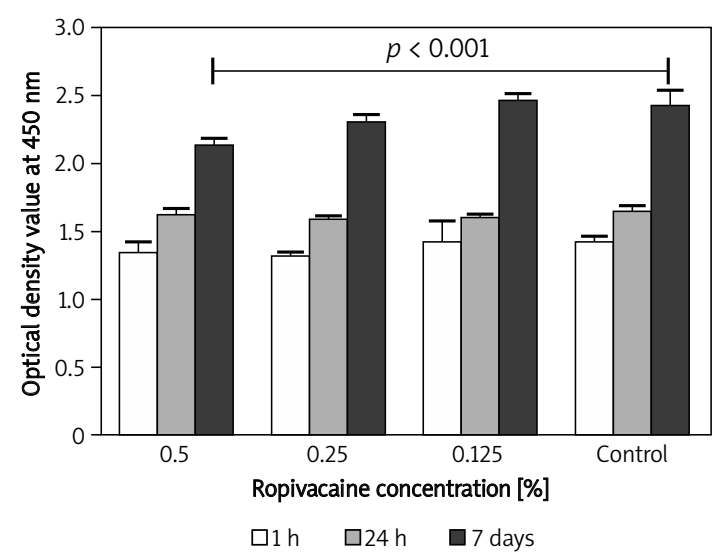

Figure 1. Bar chart with standard deviation showing a time and concentration-dependent effect on human fibroblast mitochondrial activity after 30minute exposure to ropivacaine. A significant difference in mitochondrial activity was only detectable after 7 days in the $0.5 \%$ ropivacaine group

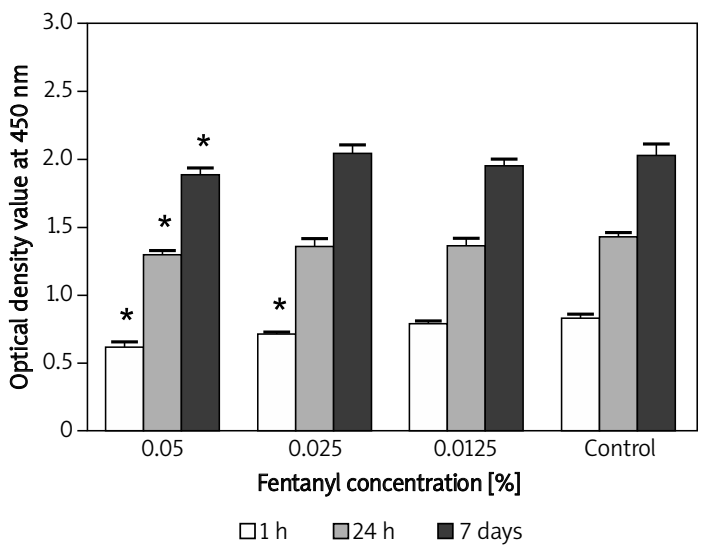

Figure 2. Bar chart with standard deviation showing a time and concentration-dependent effect on human fibroblast mitochondrial activity after 30minute exposure to fentanyl. A significant difference in mitochondrial activity was detectable after $1 \mathrm{~h}$, $24 \mathrm{~h}$ and 7 days in the $0.05 \%$ group and after 1 hour in the $0.025 \%$ group ( ${ }^{*} p<0.05$ vs. DMEM-only)

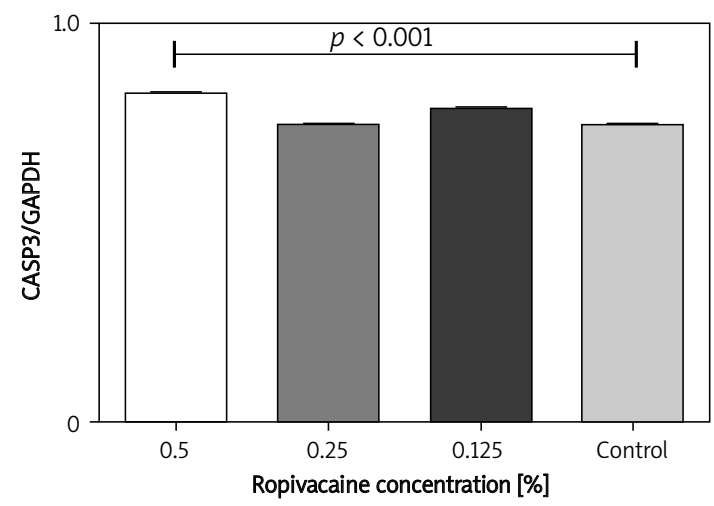

Figure 3. Bar chart with standard deviation demonstrating significant elevation of caspase- 3 after 7 days when human fibroblasts were exposed to $0.5 \%$ ropivacaine for $30 \mathrm{~min}$
FastStart DNA Master SYBR Green I Kit (Roche Applied Science). One $\mu$ l of the $1 / 10$ diluted sample was used for the quantitative two-step PCR. The following protocols were used: GAPDH and caspase3 (a 10 -min step at $95^{\circ} \mathrm{C}$, followed by 40 cycles of $60 \mathrm{~s}$ at $60^{\circ} \mathrm{C}$ and $15 \mathrm{~s}$ at $72^{\circ} \mathrm{C}$ ); and PARP-1 (a 10 min step at $94^{\circ} \mathrm{C}$, followed by 40 cycles of $60 \mathrm{~s}$ at $60^{\circ} \mathrm{C}$ and $10 \mathrm{~s}$ at $72^{\circ} \mathrm{C}$ ). Reactions were performed twice and relative quantification of the target gene expression was generated normalizing to GAPDH.

\section{Statistical analysis}

For statistical comparison of cell viability and apoptosis marker, data were analysed by one-way analysis of variance (ANOVA) followed by Bonferroni $t$-test (Prism, GraphPad Software Inc, San Diego, California). A probability of $p<0.05$ was considered statistically significant.

\section{Results}

\section{Mitochondrial activity}

Mitochondrial activity of fibroblasts after 30-minute exposure to $0.5 \%$ ropivacaine was significantly $(p<0.001)$ decreased after 7 days when compared with the control group (Figure 1). There was no aberration at earlier times and mitochondrial activity of human fibroblasts after exposure to $0.25 \%$ and $0.125 \%$ ropivacaine was similar to that of the DMEM-only control group for $60 \mathrm{~min}, 24 \mathrm{~h}$ and 7 days $(p>0.05)$. As shown in Figure 2, exposure of $0.05 \%$ fentanyl to human fibroblasts induced a significant $(p<0.001)$ decrease of mitochondrial activity at each tested time point (1 h, 24 h, 7 days). In addition, activity in the $0.025 \%$ fentanyl group was significantly lower when compared to the control group after $1 \mathrm{~h}$.

\section{Apoptosis rate}

To assess the induction of apoptosis, the levels of caspase- 3 and PARP-1 were evaluated at each point of time ( $1 \mathrm{~h}, 24 \mathrm{~h}, 7$ days). A significantly ( $p<$ 0.05 ) higher level of caspase- 3 was only found in fibroblasts 7 days after treatment with $0.5 \%$ ropivacaine (Figure 3 ). The level of PARP-1 at that moment was not significantly different from the control group. There were no significant differences in apoptosis marker levels in any of the groups treated with fentanyl.

\section{Discussion}

Postoperative pain management following knee or shoulder arthroscopy can be a challenge of its own. Intra-articular injection of local anaesthetics is regularly used to enhance postoperative analgesia following arthroscopy and has been shown to offer effective and safe postoperative pain relief 
[1-3]. However, several studies and case reports have described cytotoxic effects of local anaesthetics on chondrocytes $[3,5,7,18]$. Previous studies focused on the impact of local anaesthetics on chondrocytes although fibroblasts play a crucial role in tissue healing and might be aggrieved by the injected analgesic agent as well. This study was conducted because only sparse data exist on the effect of ropivacaine on human fibroblasts $[1,15]$ and until now no data exist on the effect of fentanyl on human fibroblasts.

As a natural part of the process of tissue regeneration, fibroblasts play an important role in the proliferative phase as they migrate from normal tissue into the wound area to represent the most common cells of connective tissue. In addition to chondroblasts and osteoblasts, they are the primary producers of collagen. Fibroblasts furthermore synthesize the ground substance of the extracellular matrix in which the cells of the connective tissue and the different types of fibres are embedded and express adhesion molecules and fibroblastic markers, and secrete growth factors and cytokines [19]. Due to the crucial role of fibroblasts in the complex process of tissue healing, we were interested if and how these cells are affected by drugs that are commonly used for intra-articular analgesia since the main focus in previous studies were chondrocytes.

We chose ropivacaine as an amide-type local anaesthetic because it has been shown to be as effective as bupivacaine but less toxic and furthermore is widely used in musculoskeletal medicine [1, $3,20]$. Fentanyl on the other hand has been used for intra-articular analgesia with favourable outcomes $[9,10,12]$ but toxicity to fibroblasts has never been investigated.

The most important finding of the present study was that both drugs have a detrimental effect on human fibroblasts, depending on the time and concentration. This effect was more distinct in fentanyl.

We chose to determine fibroblast viability by quantifying mitochondrial activity [21, 22]. Furthermore, we evaluated the expression of apoptosis markers such as caspase- 3 and Parp- 1 to elucidate drug-induced initiation or execution of apoptosis [21].

In our experiment, we noted a significant $(p<$ $0.001)$ decrease of mitochondrial activity 7 days after exposure to $0.5 \%$ ropivacaine when compared to the control group. Previous studies have found a concentration-dependent adverse effect of ropivacaine on mitochondrial activity and cell proliferation in human fibroblasts $[1,23]$. At the same point of time, we found a significant increase of caspase3 as a marker of apoptosis in this same group. Fedder et al. [1] were able to demonstrate the same increase in caspase-3 3 days after exposure to ropivacaine.
On the other hand, fibroblast mitochondrial activity was already significantly $(p<0.001)$ decreased when exposed to $0.05 \%$ fentanyl after $1 \mathrm{~h}$. This effect was also measurable after $24 \mathrm{~h}$ and 7 days. Furthermore, we also noted a significant $(p<0.001)$ decrease of mitochondrial activity $1 \mathrm{~h}$ after exposure to $0.025 \%$ fentanyl. Since apoptosis markers were not increased at any time, one might assume that fentanyl has a quick but not very powerful effect on human fibroblasts, not leading to apoptosis. This hypothesis can be supported by Haasters et al. [24], who did not find a significant difference in apoptosis markers after exposing hamstring-derived progenitor cells to ropivacaine when compared with a control group. But on the other hand, the hypothesis can be dismissed by some studies that postulate caspase-independent mechanisms of cell death due to changes in intracellular $\mathrm{Ca}^{2+}$ dysregulation [25-28].

Either way, the results of the present study demonstrated that 30-minute exposure to $0.5 \%$ ropivacaine in vitro causes a decrease of fibroblast mitochondrial activity and an increase of caspase3 in the highest concentration after 7 days whereas fentanyl in any concentration decreases mitochondrial activity right away.

However, there are some limitations of the present study. First of all, this in vitro model cannot represent postoperative intra-articular conditions such as postoperative bleeding, active blood supply, cell metabolic activities or the amount of synovial fluid. Furthermore, because it is an in vitro model, the observations cannot necessarily be applied directly in vivo. Nevertheless, the standardized in vitro setup provided highly reproducible results in terms of substance-specific effects on cell viability, metabolic activity, and induction of apoptosis. The consequences of intra-articular application of ropivacaine and fentanyl on fibroblasts require further investigation. Further studies have to evaluate these effects probably even closer to the cell membrane. One option is to determine the expression of inducible nitric oxide synthase (iNOS), which begins to synthesize a great quantity of nitrogen oxide shortly after induction. Overproduction of nitric oxygen, a free radical, damages cellular components, including lipids, which results in declining physiological function and cell death [29, 30]. In addition, the results of our study should be clarified in an animal model.

In conclusion, these data suggest that both drugs do have a concentration-dependent effect on mitochondrial activity in human fibroblasts in vitro in varying degrees. Because of the immediate effects of fentanyl on mitochondrial activity but without the anticipated increase of caspase- 3 as an apoptosis marker, the toxicity remains unclear. Therefore, we cannot support fentanyl as an alter- 
native to ropivacaine. Further studies will still have to prove the benefit of opioids in intra-articular analgesia.

\section{References}

1. Fedder C, Beck-Schimmer B, Aguirre J, et al. In vitro exposure of human fibroblasts to local anaesthetics impairs cell growth. Clin Exp Immunol 2010; 162: 280-8.

2. Jacobs TF, Vansintjan PS, Roels $N$, et al. The effect of Lidocaine on the viability of cultivated mature human cartilage cells: an in vitro study. Knee Surg Sports Traumatol Arthrosc 2011; 19: 1206-13.

3. Piper SL, Kim HT. Comparison of ropivacaine and bupivacaine toxicity in human articular chondrocytes. J Bone Joint Surg Am 2008; 90: 986-91.

4. Moiniche S, Mikkelsen S, Wetterslev J, Dahl JB. A systematic review of intra-articular local anesthesia for postoperative pain relief after arthroscopic knee surgery. Reg Anesth Pain Med 1999; 24: 430-7.

5. Chu CR, Izzo NJ, Papas NE, Fu FH. In vitro exposure to $0.5 \%$ bupivacaine is cytotoxic to bovine articular chondrocytes. Arthroscopy 2006; 22: 693-9.

6. Dogan N, Erdem AF, Erman Z, Kizilkaya M. The effects of bupivacaine and neostigmine on articular cartilage and synovium in the rabbit knee joint. J Int Med Res 2004; 32: 513-9.

7. Hansen BP, Beck CL, Beck EP, Townsley RW. Postarthroscopic glenohumeral chondrolysis. Am J Sports Med 2007; 35: 1628-34.

8. Petty DH, Jazrawi LM, Estrada LS, Andrews JR. Glenohumeral chondrolysis after shoulder arthroscopy: case reports and review of the literature. Am J Sports Med 2004; 32: 509-15.

9. Kalso E, Tramer MR, Carroll D, McQuay HJ, Moore RA. Pain relief from intra-articular morphine after knee surgery: a qualitative systematic review. Pain 1997; 71: 127-34.

10. Kazemi AP, Rezazadeh S, Gharacheh HR. Pain relief after arthroscopic knee surgery: intraarticular sufentanil vs morphine. Middle East J Anesthesiol 2004; 17: 1099-112.

11. Kizilkaya M, Yildirim OS, Dogan N, Kursad H, Okur A. Analgesic effects of intraarticular sufentanil and sufentanil plus methylprednisolone after arthroscopic knee surgery. Anesth Analg 2004; 98: 1062-5.

12. Vranken JH, Vissers KC, de Jongh R, Heylen R. Intraarticular sufentanil administration facilitates recovery after daycase knee arthroscopy. Anesth Analg 2001; 92: 625-8.

13. Stein C, Comisel K, Haimerl E, et al. Analgesic effect of intraarticular morphine after arthroscopic knee surgery. N Engl J Med 1991; 325: 1123-6.

14. Stein C, Millan MJ, Yassouridis A, Herz A. Antinociceptive effects of mu- and kappa-agonists in inflammation are enhanced by a peripheral opioid receptor-specific mechanism. Eur J Pharmacol 1988; 155: 255-64.

15. Pescosolido N, Scarsella G, Tafani M, Nebbioso M. Cataract surgery complications: an in vitro model of toxic effects of ropivacaine and lidocaine. Drugs in R\&D 2011; 11: 303-7.

16. Birkenmaier C, Redeker J, Sievers B, Melcher C, Jansson V, Mayer-Wagner $S$. An evaluation of medications commonly used for epidural neurolysis procedures in a human fibroblast cell culture model. Reg Anesth Pain Med 2011; 36: 140-4.

17. Vandesompele J, De Preter K, Pattyn F, et al. Accurate normalization of real-time quantitative RT-PCR data by geometric averaging of multiple internal control genes. Genome Biol 2002; 3: RESEARCH0034.
18. Anderson SL, Buchko JZ, Taillon MR, Ernst MA. Chondrolysis of the glenohumeral joint after infusion of bupivacaine through an intra-articular pain pump catheter: a report of 18 cases. Arthroscopy 2010; 26: 451-61.

19. Kisseleva T, Brenner DA. Mechanisms of fibrogenesis. Exp Biol Med (Maywood) 2008; 233: 109-22.

20. Scherb MB, Han SH, Courneya JP, Guyton GP, Schon LC. Effect of bupivacaine on cultured tenocytes. Orthopedics 2009; 32: 26.

21. Unami A, Shinohara Y, Ichikawa T, Baba Y. Biochemical and microarray analyses of bupivacaine-induced apoptosis. J Toxicol Sci 2003; 28: 77-94.

22. Cela O, Piccoli C, Scrima R, et al. Bupivacaine uncouples the mitochondrial oxidative phosphorylation, inhibits respiratory chain complexes I and III and enhances ROS production: results of a study on cell cultures. Mitochondrion 2010; 10: 487-96.

23. Martinsson T, Haegerstrand A, Dalsgaard CJ. Ropivacaine and lidocaine inhibit proliferation of non-transformed cultured adult human fibroblasts, endothelial cells and keratinocytes. Agents Actions 1993; 40: 78-85.

24. Haasters F, Polzer H, Prall WC, et al. Bupivacaine, ropivacaine, and morphine: comparison of toxicity on human hamstring-derived stem/progenitor cells. Knee Surg Sports Traumatol Arthrosc 2011; 19: 2138-44.

25. Brun A. Effect of procaine, carbocain and xylocaine on cutaneous muscle in rabbits and mice. Acta Anaesthesiol Scand 1959; 3: 59-73.

26. Foster AH, Carlson BM. Myotoxicity of local anesthetics and regeneration of the damaged muscle fibers. Anesth Analg 1980; 59: 727-36.

27. Gomez-Arnau JI, Yanguela J, Gonzalez A, et al. Anaesthesia-related diplopia after cataract surgery. $\mathrm{Br} J$ Aanaesth 2003; 90: 189-93.

28. Zink W, Graf BM. Local anesthetic myotoxicity. Reg Anesth Pain Med 2004; 29: 333-40.

29. Bentz M, Zaouter C, Shi Q, et al. Inhibition of inducible nitric oxide synthase prevents lipid peroxidation in osteoarthritic chondrocytes. J Cell Biochem 2012; 113: 2256-67.

30. Sharpe MA, Ollosson R, Stewart VC, Clark JB. Oxidation of nitric oxide by oxomanganese-salen complexes: a new mechanism for cellular protection by superoxide dismutase/catalase mimetics. Biochem J 2002; 366: 97-107. 